\title{
Study on MnS Precipitation Thermodynamics of DL05 Cable Steel
}

\author{
Qichun Peng ${ }^{1}$, Chunquan $\mathrm{Liu}^{1}$, Li Deng ${ }^{1}$, Jingbo $\mathrm{Xu}^{2}$, Tianhui $\mathrm{Xi}^{2}$ and $\mathrm{Wei}^{2}{ }^{2}$ \\ ${ }^{1}$ Key Laboratory of Ferrous Metallurgy and Resources Utilization, Ministry of Education, Wuhan University of Science and \\ Technology, 430081, Wuhan, China \\ ${ }^{2}$ Wuhan Iron and Steel(Group) Company, Wuhan 430083
}

\begin{abstract}
R\&D of the DL05 cable steel are briefly introduced, then, the influence of element $M n$ and $S$ on the electrical conductivity of DL05 cable steel are presented in details. some Key thermal properties and controlled manganese-sulphurratio in steel of the DL05 cable steel have been researched by using the mathematical including liquid, solidus temperature, the $\mathrm{MnS}$ precipitation temperature under different sulfur content, $\delta$-Fe and $\gamma$-Fe allotrope transformation point temperature etc, which can provide references for the large-scale industrial production of the steel.
\end{abstract}

Keywords-DL05.cable steel; electrical conductivity; manganese-sulphurratio; precipitated thermodynamics

\section{INTRODUCTION}

With the gradual deepening of China's modernization construction, gross domestic product(GDP) has jumped to the second place in the world, the skills change rapidly in manufacturing areas, so the user's demands are higher and higher to the iron and steel products' quality and performance as one of the necessary raw materials, DL05 cable steel produced by a steel plant is a typical product with quality performance guaranteed. Therefore, here are important theoretical significance and practical application value to do the further study on the conductive mechanism of DL05 cable steel., the relationship between chemical composition, grain size and electrical conductivity for DL05 cable steel electrical conductivity's assurance and improvement. The advantage of D0L5 steel cable contain of steel tensile strength, toughness and copper conductive, the tensile strength, toughness is two times that of pure copper, quality than that of pure copper wire light 12 , it has low cost, small resistance conductive rate, saving valuable non-ferrous metal resources etc., the demand increased year by year. According to statistics, the conductivity of the steel for each additional 100, per ton of steel can reduce their consumption of 800 yuan of copper.

Based on the data measured in production scene, the research results that there is a direct relationship between electrical conductivity and chemical composition by analyzing the data. Data analysis shows that the higher $\mathrm{w}_{\Sigma \text { all }}, \mathrm{w}_{\Sigma(\text { C. Si. P. N) }}$, $\mathrm{w}[\mathrm{Als}], \mathrm{w}[\mathrm{Cu}], \mathrm{w}[\mathrm{Mn}]$ is, the lower electrical conductivity is, electrical conductivity is not associated with $\mathrm{w}_{\Sigma(\mathrm{Ni} \text {. Cr. Mo. Cu), }}$, $\mathrm{w}_{\sum \text { all (Excluding Mn) }}$, and manganese element has the most impact. In this paper, through the study of the thermodynamic calculation of $\mathrm{MnS}$ inclusion in DL05 steel, the precipitation probability of the steel $\mathrm{MnS}$ is evaluated, and the corresponding ratio of manganese to sulfur is obtained, which provides a theoretical basis for the control of the actual manganese sulfur ratio.

\section{EXPERIMENTAL METHODS AND ANALYSIS}

Manganese is the main element of the steel, the as a desulfurization agent used to control sulfur inclusion content in steel and combined with sulfur in liquid steel generate to $\mathrm{MnS}$, reduce sulfur harm, slightly refine microstructure, soluble in ferrite form substitution solid solution, strengthen the organization, improve the hardenability, The solid solution strengthening substrate [1]. When $\mathrm{Mn}$ is less than $1.5 \mathrm{wt} . \%$, the manganese elements to grain refinement, Strengthen the substrate, reduce the $\gamma-\mathrm{Fe}$ transition into $\alpha$-Fe phase transformation temperature and initial martensitic transformation temperature, thus increasing the number of participating in austenite, and then improve the toughness of steel [2]. The addition of manganese in the steel will form the following balance:

$$
\mathrm{Mn}+\mathrm{FeS} \leftrightarrow \mathrm{Fe}+\mathrm{MnS}
$$

The sulfur almost all steel and iron combination form the low melting point of $\mathrm{FeS}$ and $\mathrm{Fe}$ eutectics, When the manganese-sulphurratio was low to a certain value, which makes the steel plastic decrease. Increasing the Mn content in the steel will increase the probability of the combination of sulfur and manganese, and the formula (1) in the equilibrium forward movement, which can hinder the formation of $\mathrm{FeS}$ and other low melting point compounds in the austenite grain boundaries. theoretically to achieve this goal, manganese sulfur ratio to reach 7 [3-5].

The effect of non-metallic inclusions on the properties of steel is often manifested in the failure of the continuity of the matrix, the formation of notch and stress concentration, $\mathrm{MnS}$ inclusion is one of them. The precipitation of $\mathrm{MnS}$ is mainly affected by the concentration product of manganese and sulfur in steel. Early trials of DL05 steel for chemical components, as shown in the Table I.

TABLE I. CHEMICAL COMPOSITION OF STUDIED STEEL(WT.\%)

\begin{tabular}{ccccccc}
\hline $\mathrm{C}$ & $\mathrm{Si}$ & $\mathrm{Mn}$ & $\mathrm{P}$ & $\mathrm{S}$ & $\mathrm{Als}$ \\
\hline 0.0045 & 0.0037 & 0.149 & 0.012 & 0.0089 & 0.0011 \\
\hline
\end{tabular}



[6-8]:

The chemical equation for the reaction of $\mathrm{Mn}$ and $\mathrm{S}$ in steel

$$
[M n]+[S]=M n S(s)
$$

(i) Liquid phase

$$
\lg (w[M n] w[S])=\frac{8627}{T}-4.745
$$

(ii) High temperature ferrite delta phase

$$
\lg \left(w[M n]_{\delta} w[S]_{\delta}\right)=-\frac{10590}{T}+4.302-0.07 w[S i]
$$

(iii) Austenitic gamma phase

$\lg \left(w[M n]_{y} w[S]_{\gamma}\right)=-\frac{9020}{T}+2.929-\left(-\frac{215}{T}+0.0097\right) w[M n]-0.07 w[S i]$

Commonly used the liquidus and solidus computation formula is as follows[9]:

$$
\begin{aligned}
& T_{L}=1809-78 w[C]-7.6 w[S i]-4.9 w[M n]-34.4 w[P]-38 w[S] \\
& T_{S}=1665+1122 w[C]-60 w[S i]-12 w[M n]-140 w[P]-160 w[S]
\end{aligned}
$$

Here, $T_{L}$ is liquidus temperature, $T_{S}$ is solidus temperature, $\mathrm{K}$. The initial refining DL05 steel chemical composition form table 1 substituted into the formula (6), (7), can be calculated: $\mathrm{T}_{\mathrm{L}}=1806.9 \mathrm{~K}, \mathrm{~T}_{\mathrm{S}}=1664.9 \mathrm{~K}$.

\section{RESULTS AND DISCUSSION}

When the steel with $0.149 w \mathrm{wt} \% \mathrm{Mn}$ content, the precipitation temperature of $\mathrm{MnS}$ with different sulfur content is shown in Figure I. Simultaneous (3) and (4), Available gamma-Fe $\leftrightarrow$ delta-Fe allotropic transformation temperature $\mathrm{T}=1165.6 \mathrm{~K}$, which is $892.4^{\circ} \mathrm{C}$

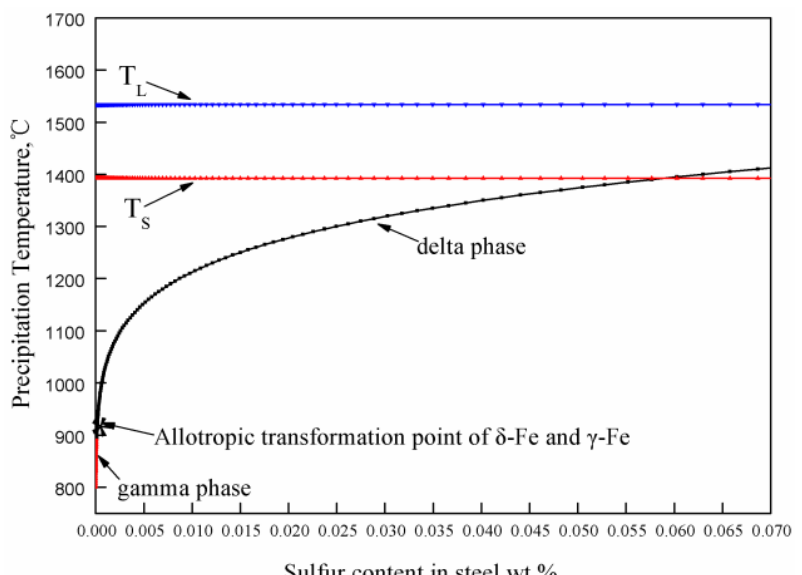

FIGURE I. RELATIONSHIP BETWEEN SULFUR CONTENT IN STEEL AND MNS PRECIPITATION TEMPERATURE
In theory, the control of sulfur content in less than $0.0577 \mathrm{wt} . \%$, can effectively reduce the precipitation probability of MnS, the steel with $0.149 \mathrm{wt} . \%$ Mn content, The content of sulfur in the critical precipitation point during the solidification process is 0.0577 wt.\% in Figure 1. Early trials of DL05 steel for chemical components, In the early trials of DL05 steel $0.0089 w t . \% S$ less than w[S] critical. Therefore, theory and the trial of DL05 steel is not affected by MnS precipitation. At the same time, it can be as the control of ratio of manganese and sulphur in steel, $\mathrm{w}[\mathrm{Mn}] / \mathrm{w}[\mathrm{S}] \geq 2.6$, can effectively control the MnS inclusion precipitation.

$\mathrm{FeS}$ and Fe eutectic formation with low melting point is the root cause of steel "hot brittleness" phenomenon. With the increase of $\mathrm{w}[\mathrm{Mn}] / \mathrm{w}[\mathrm{S}]$, the ratio of FeS to total sulfur content in steel is gradually decreased, therefore, the ratio of $\mathrm{w}[\mathrm{Mn}] / \mathrm{w}[\mathrm{S}]$ is less than 10 in Figure II. Theoretically, there is no possibility of $\mathrm{MnS}$ inclusions precipitation. Through the above thermodynamic calculation.

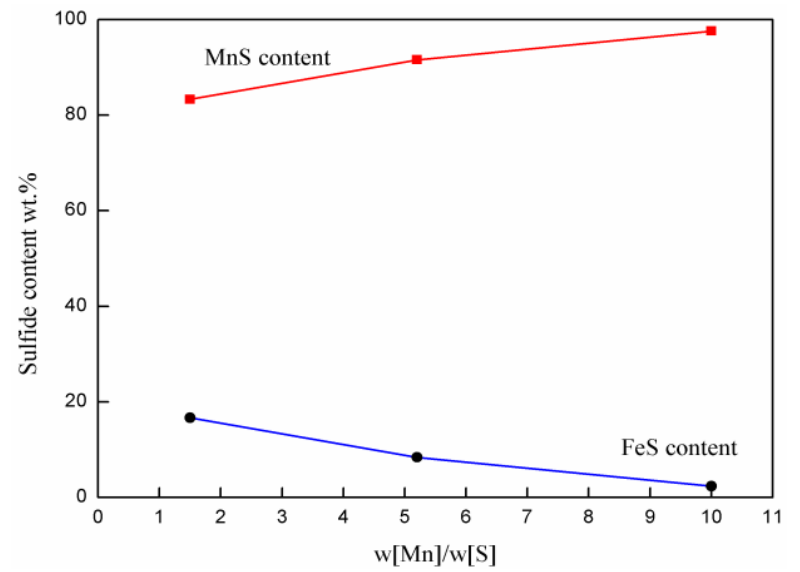

FIGURE II. RELATIONSHIP BETWEEN SULFIDE AND W[MN]/W[S] IN STEEL [10]

\section{CONCLUSIONS}

Based on electrical conductivity effect factors of DL05 Cable Steel, Key thermal properties and controlled manganese-sulphurratio in steel of the DL05 cable steel have been researched by using the mathematical.

(1) The steel $T_{L}=1806.9 \mathrm{~K}, T_{S}=1664.9 \mathrm{~K}$, was calculated by the thermodynamic formula. the trial of DL05 steel is not affected by MnS precipitation. At the same time, it can be as the control of ratio of manganese and sulphur in steel, $\mathrm{w}[\mathrm{Mn}] / \mathrm{w}[\mathrm{S}] \geq 2.6$, can effectively control the MnS inclusion precipitation.

(2) According to the thermodynamic calculation, the ratio of manganese to sulfur ratio is less than 10,to prevent the occurrence of " hot brittleness " phenomenon effectively, At the same time, to reduce the DL05 of the MnS steel matrix damage, and then as far as possible to maintain the integrity of the crystal structure, to ensure and improve the conductivity of the steel.

\section{ACKNOWLEDGEMENT}

This work was funded by the National Natural Science Foundation of China. 


\section{REFERENCES}

[1] H.Y. Wang, K.H. Zheng, D. Nong, et al., Study on the substitution of nickel and molybdenum in chromium alloy cast steel, J. Casting. 61(2012) 1287-1290.

[2] J.P. Xie, W. Li, Y.P. Song, et al., Wear resistant cast steel and melting, China Machine Press, Beijing, 2003, pp. 130-254.

[3] B. Mintz, Z. Mohamed, Influence of Manganese and Sulfur on Hot Ductility of Steels Heated Directly to Temperature, Mater. Sci. Technol. 5(1989) 1212-1219.

[4] R. Abushoha, S. Ayyad, B. Mintz, Influence of Cooling Rate and MnS Inclusions on Hot Ductility of Steels, Mater. Sci. Technol. 14(1998) 227-235.

[5] Y. Maehara, K. Yasumoto, H. Tomono, Surface cracking mechanism of continuously cast low carbon low alloy steel slabs, Mater. Sci. Technol. 6(1990) 793-806.

[6] Z. Liu, J. Wei, K. Cai, A Coupled Mathematical Model of Microsegregation and Inclusion Precipitation during Solidification of Silicon Steel, ISIJ Int. 42(2002) 958-963.

[7] A.A Kononov, B.M. Mogutnov, Effect of Carbon on Precipitation of MnS Inhibitor in Grain-Oriented 3\% Silicon-Steel, ISIJ Int. 39(1999) 64-68.

[8] C.W. Yang, N.B. Lv, X.J. Zhuo, X.H. Wang, W.J. Wang, Study on precipitation of MnS on Ti-Al composite oxides , J. Steel, 11(2010) 32-36.

[9] U. Yoshiyuki, Effect of Oxide Inclusions on MnS Precipitation in Low Carbon Steel. Telsu-to-Hagane, 75(1989) 501.

[10] W.X. Song, Metallography, China Machine Press, Beijing, 1997, pp. 3-29. 